\title{
ALTURA DO DOSSEL E INTERCEPTAÇÃO DE LUZ EM DOSSÉIS DE LEGUMINOSAS FORRAGEIRAS
}

\author{
GALZERANO, Leandro ${ }^{1 *}$ \\ MALHEIROS, Euclides Braga ${ }^{1}$ \\ MORGADO, Eliane da Silva ${ }^{1}$ \\ RUGGIERI, Ana Claudia ${ }^{1}$
}

\begin{abstract}
RESUMO: Objetivou-se com este trabalho determinar a existência de relação entre a altura do dossel e a interceptação de radiação fotossinteticamente ativa (IRFA), durante o período de rebrotação das leguminosas forrageiras Java (Macrotyloma axillare cv. Java), Soja Perene (Neonotonia wightii) e Lab-lab (Lablab purpureum). O experimento foi conduzido na Faculdade de Ciências Agrárias e Veterinárias/Unesp, Campus de Jaboticabal, São Paulo, Brazil. Para realização deste estudo foram tomados 12 pontos amostrais sobre os dosséis das forrageiras em março de 2012 quando as leguminosas Java, Soja Perene e Lab-lab se encontravam com 27, 28 e 27 dias de rebrotação (primeiro corte após adubação), respectivamente. A altura e a IRFA foram tomadas no mesmo ponto amostral. A altura do dossel foi determinada com uso de régua com graduação em centímetros e a IRFA foi aferida com sensor específico (AccuPAR Model LP - 80 PAR/LAI ceptometer) para esta faixa espectral da radiação solar (400 - $700 \mathrm{~nm}$ ). Os dados foram submetidos à análise de regressão e foi observada a existência de associação positiva entre a altura do dossel e correspondente IRFA em dosséis das leguminosas Java, Soja Perene e Lab-lab.
\end{abstract}

Palavras-chave: Ecofisiologia. Forragem. Macrotyloma axillar., Neonotonia wightii. Lablab purpureum.

SUMMARY: The aim of this study was to determine the existence of a relationship between height and canopy interception of photosynthetically active radiation (PAR) in regrowth of Java (Macrotyloma axillare cv. Java), Perennial Soybean (Neonotonia wightii) e Lab-lab (Lablab purpureum) legumes. The experiment was carried out at the Faculdade de Ciências Agrárias e Veterinárias/Unesp, Campus de Jaboticabal, São Paulo, Brazil. For this study 12 sampling points were taken on the canopies of the legumes in March 2012 when the legumes Java, Perennial Soybean and Lab-lab were with 27, 28 and 27 days of regrowth respectively. Canopy height and interception of PAR were taken at the same point. The canopy height was determined using a ruler graduated in centimeters and the interception of PAR was measured using a specific sensor (Model ACCUP LP - 80 PAR / LAI ceptometer). This study presented positive association between canopy height and interception of PAR in the Java, Perennial Soybean and Lab-lab legume swards.

Key words: Ecophysiology. Forage. Macrotyloma axillare. Neonotonia wigh. Lablab purpureum.

\section{INTRODUÇÃO}

Os pastos, devido seus baixos custos de produção em relação aos concentrados, representam à forma mais prática e econômica de alimentação de bovinos e constituem a base de sustentação da pecuária do Brasil (CUNHA et al., 2007). O uso de leguminosas forrageiras em pastos consorciados com gramíneas ou mesmo em cultivo exclusivo tem sido amplamente estudado com objetivo de suplementação da dieta dos animais e melhoria da qualidade do solo das pastagens. De acordo com Garcia et al. (2008), a introdução das leguminosas, no sistema de pastagem, aumenta o aporte do nitrogênio no solo, pela simbiose entre a leguminosa e as bactérias do gênero Rhizobium, que fixam o nitrogênio atmosférico,

\footnotetext{
${ }^{1}$ Faculdade de Ciências Agrárias e Veterinárias, Universidade Estadual Paulista - Unesp, 14884-900, Jaboticabal-SP, Brasil. *E-mail: galzeranorural@yahoo.com.br
} 
resultando em aumento na produção de biomassa da forrageira. Dentre os cultivares de leguminosa forrageira no Brasil encontra-se a Java, lançada em 2004, obtida por meio do cruzamento artificial de duas cultivares de Macrotyloma axillare, Archer e Guatá (BONFIM-SILVA et al., 2011) e que vem sendo amplamente utilizada pelos produtores. A Soja Perene (Neonotonia wightii) é uma leguminosa perene originária da África com hábito de crescimento trepador. Produz ao redor de 20 a 30 toneladas de massa verde e 6 a 8 toneladas de massa seca, por há e por ano no entanto, o crescimento inicial é um tanto lento e por isto, exige uma capina inicial. A Lab-lab (Lablab purpureus (L)) é uma leguminosa anual ou bianual, originária da África, herbácea, com inflorescência de rácemos axilares pedunculados, flores de cor branca, rosada ou violácea. Desenvolve-se, melhor, em solos bem drenados e férteis. É empregada, com êxito, como adubação verde, para restauração de terras pobres; sendo, também, utilizada como forragem nos meses de inverno (VILELA, 1998). Quanto aos estudos do uso de forrageiras na produção animal, nos últimos anos, trabalhos estão sendo conduzidos com objetivo de relacionar a altura do dossel com a interceptação de radiação fotossinteticamente ativa pelo mesmo, pois se sabe que quando o dossel intercepta 95\% da luz incidente, ele atinge a taxa de crescimento máximo da cultura (BROUGHAM, 1956) e o processo e rebrotação deve ser interrompido por corte ou pastejo.

Diante do exposto, objetivou-se com este trabalho determinar a existência de relação entre a altura do dossel e a interceptação de radiação fotossinteticamente ativa (IRFA), durante o período de rebrotação das leguminosas forrageiras Java, Soja Perene e Lab-lab.

\section{MATERIAL E MÉTODOS}

O experimento foi conduzido na Faculdade de Ciências Agrárias e Veterinárias/Unesp, Campus de Jaboticabal, SP, localizada a $21^{\circ} 15^{\prime} 22^{\prime \prime}$ ' de latitude sul, longitude de $48^{\circ} 18^{\prime} 58^{\prime}$ ' $\mathrm{W}$, a uma altitude de 595 m. O solo da área experimental foi classificado como Latossolo Vermelho (EMBRAPA, 2006). Estudouse as leguminosas forrageiras: Java (Macrotyloma axillare cv. Java), em uma área experimental de 35,0 $\mathrm{m}^{2}$, a Soja Perene (Neonotonia wightii), em uma área experimental de $35,0 \mathrm{~m}^{2}$ e a leguminosa Lab-lab (Lablab purpureum), em uma área experimental de $28,0 \mathrm{~m}^{2}$. As leguminosas foram mantida sob cortes a 7 $\mathrm{cm}$ do solo a cada 30 dias. As áreas experimentais de cada leguminosa eram próximas umas das outras e, portanto, optou-se por fazer uma coleta composta de solo a $20 \mathrm{~cm}$ de profundidades das três áreas juntas em novembro de 2011, a qual indicou as seguintes propriedades químicas: Ca: 43; Mg: 13; K: 1,7 $\mathrm{mmol} / \mathrm{dm}^{3}$; P (resina): $25 \mathrm{mg} / \mathrm{dm}^{3}$; $\mathrm{MO}: 20 \mathrm{~g} / \mathrm{dm}^{3} ; \mathrm{pH}\left(\mathrm{CaCl}_{2}\right): 5,9$ e a adubação consistiu na aplicação de $100 \mathrm{~kg} / \mathrm{ha}$ de $\mathrm{K}_{2} \mathrm{O}$ na forma de Cloreto de Potássio aplicado em única dose em fevereiro de 2012. O clima de Jaboticabal, de acordo com a classificação de Köppen é classificado como tropical do tipo Aw, mesotérmico com verão úmido e inverno seco. A precipitação pluvial durante o período experimental foi de 119,3 e 30,9 mm para os meses de fevereiro e março de 2012, respectivamente e a temperatura média do ar de 25,0 e 24,2 ${ }^{\circ} \mathrm{C}$ para os meses de fevereiro e março de 2012, respectivamente. Para realização deste estudo foram tomados 12 pontos amostrais sobre os dosséis das forrageiras em março de 2012 quando as leguminosas Java, Soja Perene e Lab-lab se encontravam com 27, 28 e 27 dias de rebrotação (primeiro corte após adubação), respectivamente. A altura e a IRFA foram tomadas no mesmo ponto amostral. A altura do dossel foi determinada com uso de régua com graduação em centímetros e a IRFA foi aferida com sensor específico (AccuPAR Model LP - 80 PAR/LAI ceptometer) para esta faixa espectral da radiação solar (400 - 700 nm) (NOBEL; LONG, 1988). Os dados foram submetidos à análise de regressão. 


\section{RESULTADOS E DISCUSSÃO}

Pela análise da Figura 1, observou-se uma relação entre altura do dossel e a interceptação de RFA, que explicou aproximadamente $70 \%$ da variabilidade total $\left(\mathrm{R}^{2}=0,74\right)$. Em seu trabalho, Brougham (1956) demonstrou que quando o nível de IRFA atinge $95 \%$ da luz incidente, o IAF atinge um valor crítico, no qual a taxa de crescimento da cultura (TCC) estaria próxima de um valor máximo e portanto, o processo de rebrotação deve ser interrompido por corte ou pastejo. A altura do dossel é uma medida de fácil obtenção e a tentativa de relacioná-la com a IRFA pode facilitar atividades práticas de manejo dos pastos.

Figura 1. Relação entre altura do dossel e interceptação da radiação fotossinteticamente ativa (IRFA) em dosséis de leguminosa Java.

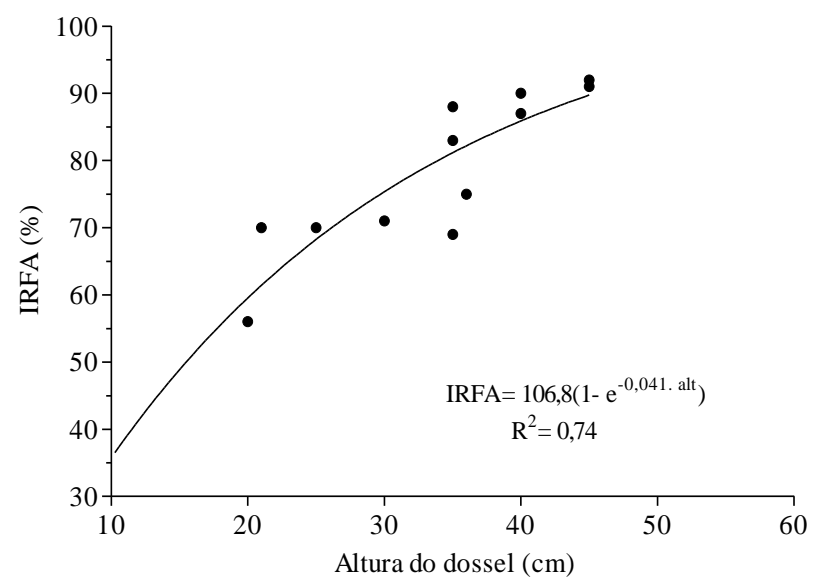

A máxima IRFA alcançada pela leguminosa Java neste estudo foi de $92 \%$, aos $45 \mathrm{~cm}$ de altura do dossel. De acordo com Galzerano et al. (2008), dosséis em crescimento livre ou mantidos sob corte resultam em maiores alturas em relação a dosséis estabilizados e mantidos sob pastejo.

Quanto à Soja Perene, pela análise da Figura 2, observou-se que a altura do dossel se relacionou com a interceptação de RFA, com equação exponencial que explicou aproximadamente $90 \%$ da variabilidade total $\left(R^{2}=0,92\right)$. Neste estudo, aos $60 \mathrm{~cm}$ de altura do dossel da Soja Perene, obteve-se a máxima IRFA de $99,0 \%$.

Figura 2. Relação entre altura do dossel e interceptação da radiação fotossinteticamente ativa (IRFA) em dosséis de Soja Perene.

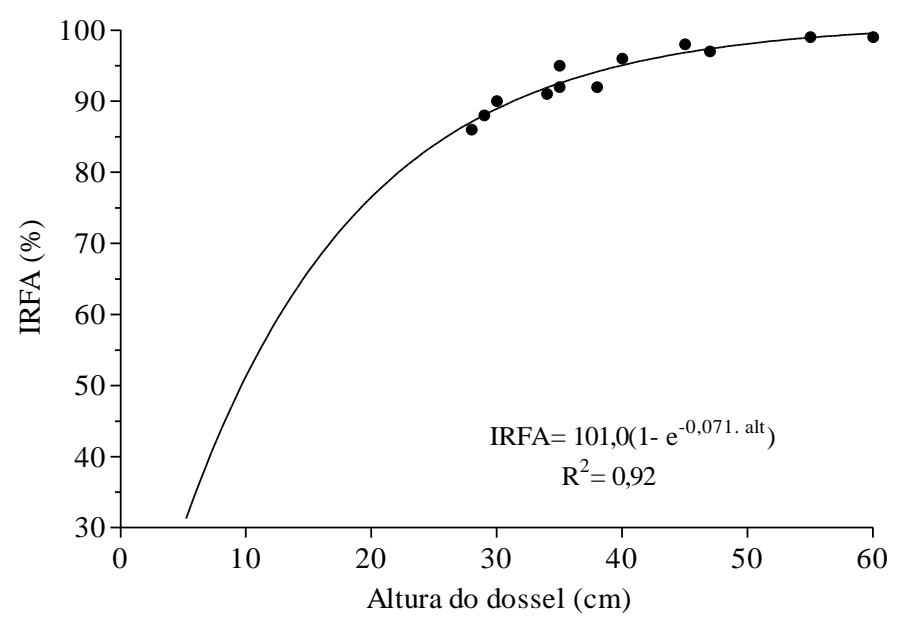


De acordo com Hodgson (1990), dentre as características do dossel que mais afetam a produção de forragem e, portanto, as mais importantes com foco no manejo são a altura do pasto, a quantidade de lâminas foliares, a massa e a densidade de forragem. Partindo dessa premissa, vários estudos têm sido realizados com foco no manejo da estrutura do dossel, tendo como principais características, a interceptação de luz, a altura do dossel e o IAF.

A relação entre a altura do dossel da leguminosa Lab-lab e a interceptação da RFA pode ser visualizada na Figura 3. Observou-se que houve relação entre altura do dossel e a interceptação de RFA, a qual explicou aproximadamente $70 \%$ da variabilidade total com $R^{2}=0,74$. Mas há que se atentar que embora muitos estudos tenham sido realizados relacionando as características do dossel, principalmente a altura com a IL, Laca e Lemaire (2000) alertam que tanto as características verticais como as horizontais da estrutura do dossel, são relevantes devido ao espaço limitado à extensão das interações planta-planta e à seleção de dietas no sentido vertical e horizontal pelos herbívoros. Assim, é possível que haja relação direta entre algumas características do dossel porém, nem sempre as respostas serão constantes, uma vez que as plantas respondem rapidamente a mudanças de ambiente e desfolhação, por exemplo, com mudanças na estrutura do dossel para melhor se adaptarem às condições impostas.

Figura 3. Relação entre altura do dossel e interceptação da radiação fotossinteticamente ativa (IRFA) em dosséis de leguminosa Lab-lab.

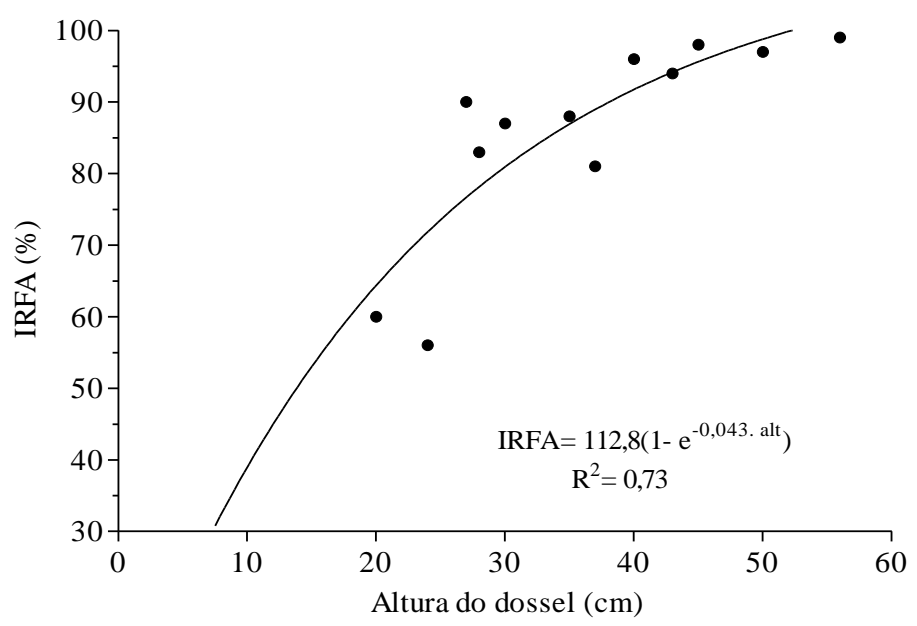

Na leguminosa Lab-lab, a máxima IRFA obtida neste estudo foi de $97 \%$, aos 50,0 $\mathrm{cm}$ de altura do dossel.

Dentre as três leguminosas estudadas e quando comparadas a 95\% de IRFA, a Java foi a que apresentou maior altura do dossel, de $48 \mathrm{~cm}$, seguida pela Lab-lab com $45 \mathrm{~cm}$, ambas com 27 dias de rebrotação e por fim, a Soja Perene com altura do dossel $43 \mathrm{~cm}$ e 28 dias de rebrotação. Galzerano et al. (2011), em estudo relacionando a altura do dossel com a interceptaçào de luz (IRFA) da gramínea forrageira, capim-xaraés (Brachiaria brizantha) verificaram a existência de relação positiva entre essas características, no entanto, nas condições as quais o estudo foi realizado, o capim-xaraés precisou de 45 dias e $58 \mathrm{~cm}$ de altura do dossel para atingir os mesmos 95\% de IRFA. Esses resultados corroboram o que disseram Laca e Lemaire (2000) que diferentes plantas forrageiras respondem de maneiras também diferentes as condições ambientais e de desfolhação a elas impostas. 


\section{CONCLUSÃO}

Foi observada a existência de associação positiva entre a altura do dossel e correspondente IRFA em dosséis das leguminosas Java, Soja Perene e Lab-lab.

\section{REFERÊNCIAS}

BONFIM-SILVA, E.M. et al. Produção e morfologia da leguminosa Java submetida a adubação fosfatada. Enciclopédia Biosfera, Centro Científico Conhecer - Goiânia, v.7, n.12, p. 1-10, 2011.

BROUGHAM, R. W. Effects of intensity of defoliation on regrowth of pasture. Australian Journal Agricultural Research. v. 7, p. 377-387, 1956.

CUNHA, F.F. et al. Características morfogênicas e perfilhamento do Panicum maximum Jacq. cv. tanzânia irrigado. Ciência e Agrotecnologia, v. 31, n. 3, p. 628-635, 2007.

EMBRAPA - EMPRESA BRASILEIRA DE PESQUISA AGROPECUÁRIA. Sistema Brasileiro de Classificação de Solos. Brasília: EMBRAPA, 2006. 306p.

GALZERANO, L. et al. Desenvolvimento das características do dossel do capim-xaraés e suas interrelações. Scientia Plena, v. 7, n. 11, p. 1-5, 2011.

GALZERANO, L. et al. Mudanças em atributos estruturais de dosséis do capim-tifton 85 na fase de estabelecimento, induzidas pela adubação nitrogenada. Boletim de Indústria Animal, v.65, n.4, p. 329336, 2008.

GARCIA, F.M. et al. O uso de estilosantes campo grande em consórcio com braquiarinha (Brachiaria decumbens). Revista Científica Eletrônica de Agronomia, v.7, n.13, p.1-8, 2008.

HODGSON, J. Grazing management: science into practice. New York: John Wiley; Longman Scientific and Technical, 1990. 203p.

LACA, E. A.; LEMAIRE, G. Measuring sward structure. In: `T MANNETJE, L.; JONES, R. M. (Ed.). Field and laboratory methods for grassland animal production research. Wallingford: CABI International, 2000. p.103-122.

NOBEL, P. S. ; LONG, S. P. Estructura del dosel e intercepción de luz. In: COOMBS, J. et al. Técnicas em Fotosíntesis y Bioproductividad. Colégio de Postgraduados, Chapingo, México, 1988. p. 34-41.

VILELA, H. Escolha de espécies forrageiras: formação de pastagens. Viçosa: CPT, 1998. 98p. 
